\title{
Traveller Perceptions of Trust in Air Traffic Controllers: A Cultural Comparison between India and the United States
}

\author{
Rian Mehta (Corresponding author) \\ Florida Institute of Technology, College of Aeronautics \\ Melbourne, FL. 32901 USA \\ E-mail: rmehta2009@fit.edu
}

Stephen Rice

Florida Institute of Technology, College of Aeronautics

Melbourne, FL. 32901 USA

Natasha Rao

Florida Institute of Technology, College of Aeronautics

Melbourne, FL. 32901 USA

Received: December 17, 2015 Accepted: January 15, 2016 Published: February 17, 2016

doi:10.5296/ijssr.v4i1.8672 URL: http://dx.doi.org/10.5296/ijssr.v4i1.8672

\begin{abstract}
The aim of this research is to determine passengers' trust in air traffic controllers, based on the age and gender of the controller. The job of an air traffic controller is difficult in terms of the physical and mental stressors involved. The retirement age for controllers was instated in an effort to avoid issues relating to lack of capabilities. Decline in trust in an aging workforce has become a trend in certain areas. Similarly, gender inequality in the workplace and the sentiment that female employees are not as capable as males is an issue experienced the world over. 376 participants from India and the United States were asked to assess their level of trust in an air traffic controller during an emergency situation. The data suggested that the
\end{abstract}


American participants trusted the older controller (55 years old) more than the younger counterparts ( 25 years old) regardless of gender. However, the Indian participants trusted the younger controllers more than the older counterparts as long as they were male. A mediation analysis found that affect mediated the relationship for the American participants but not for the Indians. This implies that the Americans were basing their trust on emotions.

Keywords: Trust, Air traffic controllers, Age, Gender

\section{Introduction}

The control of air traffic and the necessity to assist pilots has been a part of aviation from the very early years. The growth of aviation was exponential only a few years after the first flight of the Wright brothers. Since that time, air traffic controllers have become a vital resource to ensure smooth operations within the National Airspace System. The sheer volume of air traffic would not be able to fly without the coordination and assistance offered by air traffic controllers.

There are over 15000 air traffic controllers in the United States alone, and they are responsible for the safety of approximately 700 million passengers and 60 million aircraft annually (NATCA). Directly associated with this responsibility of so many peoples' lives comes several physical and mental stressors. Being an air traffic controller requires a great deal of patience and vigilance, and so they must be physically and mentally up to the task (Salden, Paas, Broers, \& Van Merriënboer, 2004). In order to account for the same, the United States government has a mandatory retirement age of 56 years for air traffic controllers (McCann, 2003). While the retirement age of their Indian counterparts is 60 years of age.

These age restrictions were founded in both cases in the spirit of safety. However, on the other hand, an age restriction and a mandatory retirement age may be deemed as a lack of trust in an aging controller to perform their duties adequately and to the highest level. A snowball effect that has been emerging from this situation is that there is a large requirement for air traffic controllers due to the high number of retirements and the increase need for controllers to account for the expansion of the aviation system. A great influx of new young air traffic controllers is the immediate solution to the shortage, while another alternative would be to increase the mandatory retirement age of the controllers. This decision should not be made lightly, but after all implications have been evaluated. It may be determined that an increase in the retirement age would be a risk. One potential risk could be that an elderly person may not be able to cope with the physical and mental demands of the job.

\section{Background}

There are multiple goals of the study which primarily center around the purpose to determine passengers' trust in air traffic controllers, based on the age and gender of the controller. In attempting to do so, this study will try to gauge the perceptions of the travelling public on air traffic controllers based on the age and gender of the controller. For the purpose of this study the travelling public refers to all current and potential airline customers. These individuals may be referred to as passengers, travellers, or consumers within the aviation industry. The 
study measures their perception of the controller by their self-reported level of trust in the controller. An additional area of focus of this research is the cross-cultural analysis, which compares the data from the Indian and American participants to identify any cultural differences in perceived trust that may exist between participants from the two nationalities. Lastly, the study also includes a mediation analysis using affect as a potential mediator. The purpose behind this is to measure whether affect, or emotion, is playing a role in the participants' decision making process and thereby influencing their trust in the controller.

\subsection{Social Stigma: Prejudice in Age and Gender}

In order to better understand the perceptions of the traveller, it is important to understand the stigmas affixed by society on certain age and gender categories. Stereotypes are psychological constructs and are often times grounded in societal teachings. Several research studies (Ashmore \& Del Boca, 1981; Brigham, 1971; Stroebe \& Insko, 1989) define stereotype as "a set of beliefs about the personal attributes of a group of people". While the term stereotypes are often associated with negative thoughts, positive stereotypes do also exist. The focus of this research is to gain a better understanding of different cultures' perceptions of age and gender as they relate to the technical task of air traffic control. Differences based on culture may exist between the two participant groups, but certain prejudices may be universally believed by both individualistic and collectivistic cultures alike (Cuddy, Norton, \& Fiske, 2005).

Two research studies (Bugental \& Hehman, 2007; Cuddy, Norton, \& Fiske, 2005) suggested that in relation to age, both positive and negative stereotypes exist. Namely, that while elderly people are considered to be friendlier and warm, they are also perceived as being weak and incompetent. The stigma that older people were deemed to be less competent was supported by additional studies as well (Kite \& Johnson, 1988; Kite, Stockdale, Whitley, \& Johnson, 2005). Levy and Banaji (2002) defined ageism as "an alteration of feeling belief, or behavior in response to an individual's or group's perceived chronological age" (p. 50). This ageism is associated with the social stigma because a person belonging to this group, in this case of an elderly age, is then deemed to possess all the stereotypical traits of certain members of that group, which may lead to social, interpersonal, and economic hindrances (Crocker, Coelkl, Testa, \& Major, 1991; Crocker, Major, \& Steele, 1998; Jones et al., 1984). These issues relating to ageism also manifest themselves within the workforce. Assertiveness and confidence are traits highly desired by the majority of the workforce, and these traits are said to exist more prevalently within younger individuals (Deaux \& Miele, 1991; Eagly \& Steffen, 1984; Gekoski \& Knox, 1990). This could pose an issue as by the year 2020, 39\% of the workforce is projected to be over the age of 55 (Rupp, Vodanovich, \& Crede, 2006; Williams $\&$ Nussbaum, 2001). On the other hand, Cleveland and Landy (1983) stated that there was no correlation between an individual's age and job performance. Therefore it could be stated that this workplace stigma and negative stereotype could create a false perception in the eyes of others, and could lead to certain individuals being unfairly deemed to be less capable (McCann \& Giles, 2002). While gender issues is another avenue of this research, it is important to note that research suggests age stereotypes tend to be more pronounced than gender stereotypes (Kite, Deaux, \& Miele, 1991). 
Similar to ageism and the stigmas associated with older age is the prejudice experienced on the basis of gender. Negative gender stereotypes have been prevalent in the workplace and even in society for that matter, for decades. The most general and overarching negative view of women is that they are not perceived to be emotionally equal to men. A 1981 study by Jackman and Senter stated that 78 percent of men shared this belief. However, this sentiment is not exclusive to males, as an almost equivalent percentage of women were found to believe the same. These ideas are additionally not exclusive to one country or region, as Williams et al. $(1999,2000)$ showed that while surveying citizens of 27 countries, the common mindset reflected these stigmas, where men were considered to be more outgoing, and women to be more agreeable. As mentioned earlier, these perception extend into the workplace, where there is a prominent segregation based on gender. These disparities often manifest themselves in terms of levels of responsibilities offered to women, and even in terms of scale of pay. Surprisingly, these disparities are especially prominent in wealthy, industrialized countries (Blackburn, Browne, Brooks, \& Jarman, 2002). This study does endeavor to find similarities and differences in consumer perceptions, and so it is important to note where these stigmas may differ. While gender issues are prevalent almost the world over, India, being a more patriarchal society, tends to be more prone to gender bias.

\subsection{Cultural Considerations}

The United States and India differ from each other not purely on their geographic positions, but also by the inherent culture and customs of their people. Culture may be explained in many different forms, and must be done so in the appropriate context of the research setting. Helmreich (2000) defined culture as "norms, values and practices, on a national, organizational, and/or professional level that are shared within a society". Another apt statement regarding culture states that it is a set of shared values and beliefs that characterize national, ethnic, moral and other group behavior (Adapa, 2008; Craig \& Douglas, 2006; Faure \& Sjostedt, 1993). For the purposes of this research, two distinct categories of culture will be the primary focus, a collectivistic cultural society and an individualistic cultural society. Both cultural groups are defined by the interactions and the relationships shared with others (Hofstede, 1980; Kongsompong et al., 2009; Triandis, 1984, 1995).

Komarraju et al. (2008) stated that members of collectivistic societies tend to have the best interests of the community as their priority. This may be manifested by way of sharing possessions or placing the needs of others within the community ahead of their own. Collectivists gain their identity by the group that they are a member of or as a part of a community. People that are raised in collectivistic cultures are taught to never question authority and to trust other members of the community without question (Han \& Shavitt, 1994). Therefore, being from a collectivistic culture may have an influence on a participant's decision-making process and thereby be a factor in understanding why people from different cultures trust in different manners. Markus and Kitayama (1991) explained that India is in large part deemed to be a more collectivistic society, where people are more interdependent on one another. This is also supported by Robbins and Judge's (2009) findings, which stated that India scored a 48 out of a 100 on the individualistic versus collectivist dimension on Hofstede's Cultural Values Index. Hofstede (1980, 2001) also claimed that according to 
studies, Thai, Chinese, and Indian cultures displayed high levels of collectivism.

On the other end of the spectrum lie members of individualistic societies as found amongst citizens of the United States. Individualists tend to have a more self-concentrated viewpoint, and tend to have their own needs and concerns as the highest priority. Bochner (1994) and Kashima and Callan (1994) explain that individualistic cultures lay an emphasis on an individual's autonomy and independence. Individualists are taught not to rely on others and encouraged to stand on their own feet. These sentiments are embodied by citizens of the United States, as evident by their scores on Hofstede's Cultural Values Index. The United States scored the highest of any country, with a 98 out of 100 .

While neither approach is deemed to be superior to the other, it is important to note that such differences in mindsets exist, as they would undoubtedly have an influence on a person's perception of people and situations. As this relates back to the current research endeavor, these cultural differences may be plausible explanations as to the differences in trust ratings of the Indian and American participants in air traffic controllers.

\subsection{Interpersonal Trust}

While air travel is deemed to be an incredibly safe mode of transportation, there is nonetheless a fear of catastrophe that surrounds the industry. For this reason, trust is important to be maintained for the industry. Gaining the trust of the passengers, in most cases is the primary priority. The success of the industry is rooted in the trust of the traveling public. After the attacks of September 11, 2001, there was a decline in air travel of $20 \%$ in the United States, during the three months following the attacks (Blunk, Clark, \& McGibany, 2006). This could be explained by the fear of the travelling public and their decline in trust in the aviation industry as a whole.

Trust can be thought of as a psychological construct that is in large part an outcome of human emotion. While there are several definitions of trust that apply to different contexts, the most apt for the context of this setting states the predictability of another person is the essence of trust (Deutsch, 1958; Eckel \& Wilson, 2004; Ergeneli, Saglam, \& Metin, 2007). Similarly, Lee and See (2004) stated that faith, and familiarity with another person or object was directly related to increased trust. Lastly, one explanation of trust states that it can be described as the relinquishment of control to another person or object with the faith of a positive outcome. This definition of trust in terms of vulnerability was put forth by Mayer et al. (1995). In the aviation industry, the traveling public, and the pilots, relinquish some control to the air traffic controllers with the faith of a positive outcome, and thereby in turn trust them to ensure their own safety. While all passengers may not personally know and therefore may not personally trust each individual controller, they exhibit group-based trust. This trust occurs when trust is placed in an individual due to their group membership (Fody, Platow, \& Yamagishi, 2009; Platow et al., 2012). However, research has shown that social stigmas may diminish trust, and can sometimes be strong enough to outweigh group-based trust (Burns, 2006; Rice, Trafimow, Hughes, \& Hunt, 2011). 


\subsection{Current Study}

Prior research has been conducted on ageism and gender stereotypes, but these psychological mindsets have not been tested in relation to consumers' perceptions of air traffic controllers. Aviation being a consumer oriented industry, it is important to gauge the perception of the travelling public and understand the trust levels of the same. Additionally, it is important to understand how these mindsets vary across the globe. Several other consumer perception studies have been conducted in the field of aviation related to passenger trust (Rice et al., 2014; Rice, Mehta, Steelman, \& Winter, 2015; Winter et al., 2015; Winter, Rice, \& Mehta, 2014).

The current study seeks to fill the gap in the previous research of this topic by further studying the relationship of trust between the traveling public and air traffic controllers. Participants were presented with hypothetical scenarios while the age and gender of the controllers were manipulated. The researchers gained ratings of affect and trustworthiness from participants from India and the United States. The hypotheses were as follows:

1) That there would be differences in trust ratings based on the country of origin of the participant.

2) That there would be differences in trust ratings based on the age of the target air traffic controllers in the scenarios.

3) That there would be differences in trust ratings based on the gender of the target air traffic controllers in the scenarios.

4) That there would be an interaction between the three independent variables; however this was a non-directional prediction.

5) That affect would mediate the relationship between the conditions and trustworthiness ratings of the air traffic controllers.

\section{Methods}

\subsection{Participants}

Three hundred seventy-six (145 females) participants from India and the United States participated in the study. The participants were recruited using the online survey tool, Amazon's ${ }^{\circledR}$ Mechanical Turk ${ }^{\circledR}$. There were equal amounts of participants from each country. The mean age was $33.71(S D=10.21)$. The mean ages did not differ as a function of country $(p>.10)$.

\subsection{Procedure, Materials and Stimuli}

Participants were first asked to fill out a consent form and then given instructions. Following this, participants were presented with a scenario about a hypothetical commercial airline flight. They were told that the air traffic controller in charge of the flight was either a 25 year old male, 25 year old female, 55 year old, or 55 year old female. Participants were then asked, "How does this make you feel?" Participants responded along three different Likert-type 
scales from extremely negative, unfavorable, bad to extremely positive, favorable, good. There was a zero neutral option for each scale.

The next step involved participants being asked, "How much would you trust this air traffic controller during an emergency situation?" and "How trustworthy do you think this air traffic controller would be during an emergency situation?" Participants were provided answers along a Likert-type scale from extremely distrust, untrustworthy to extremely trust, trustworthy, with a zero neutral option for each scale. To avoid reverse causal effects, it is important to note that the mediating variables were presented temporally prior to the outcome variables (Kenny, 2011). Lastly, participants were asked for demographics information, debriefed and dismissed. The methodology and nature of questions used in the survey were modeled after previous studies in the consumer perceptions field (Rice et al., 2014; Rice, Mehta, Steelman, \& Winter, 2015; Winter et al., 2015; Winter, Rice, \& Mehta, 2014).

\subsection{Design}

A three-way between-participants factorial design was employed, whereby the three independent variables were: 1) age of the air traffic controller; 2) gender of the air traffic controller; and 3) country of origin of the participants. A three way ANOVA was conducted using the averaged affect scores as the dependent variable. A second three way ANOVA was conducted using the averaged trust scores as the dependent variable.

\section{Results}

A Cronbach's Alpha test was conducted on the affect data to determine the level of internal consistency. The values ranged from .89 to .99 . Due to high internal consistency between the scores, the affect data was combined for further analyses. The same was performed for the trust data, as the scores ranged from .84 to .98 .

A three-way ANOVA was conducted on the Affect data, with Age of the air traffic controller, Gender of the air traffic controller, and Country of origin of the participants as the factors. There was a main effect of Age, $F(1,368)=4.48, p=.035$, partial-eta squared $=.012$, which suggest that the participants trusted the older controllers more than the younger controllers (Figure 1). There was also a main effect of Country, $F(1,368)=11.90, p<.001$, partial-eta squared $=.031$, which suggests that Indians had more positive feelings towards the younger air traffic controllers, as compared to the Americans (Figure 1). However, these effects were qualified by a significant interaction between Age and Country, $F(1,368)=5.72, p=.017$, partial-eta squared $=.015$, which suggests that American participants felt more positively about older controllers regardless of gender, while the Indian participants felt more positively about younger controllers so long as they were male. There was additionally a three-way interaction between Country, Gender, and Age, $F(1,368)=5.45, p=.020$, partial-eta squared $=.015$. 


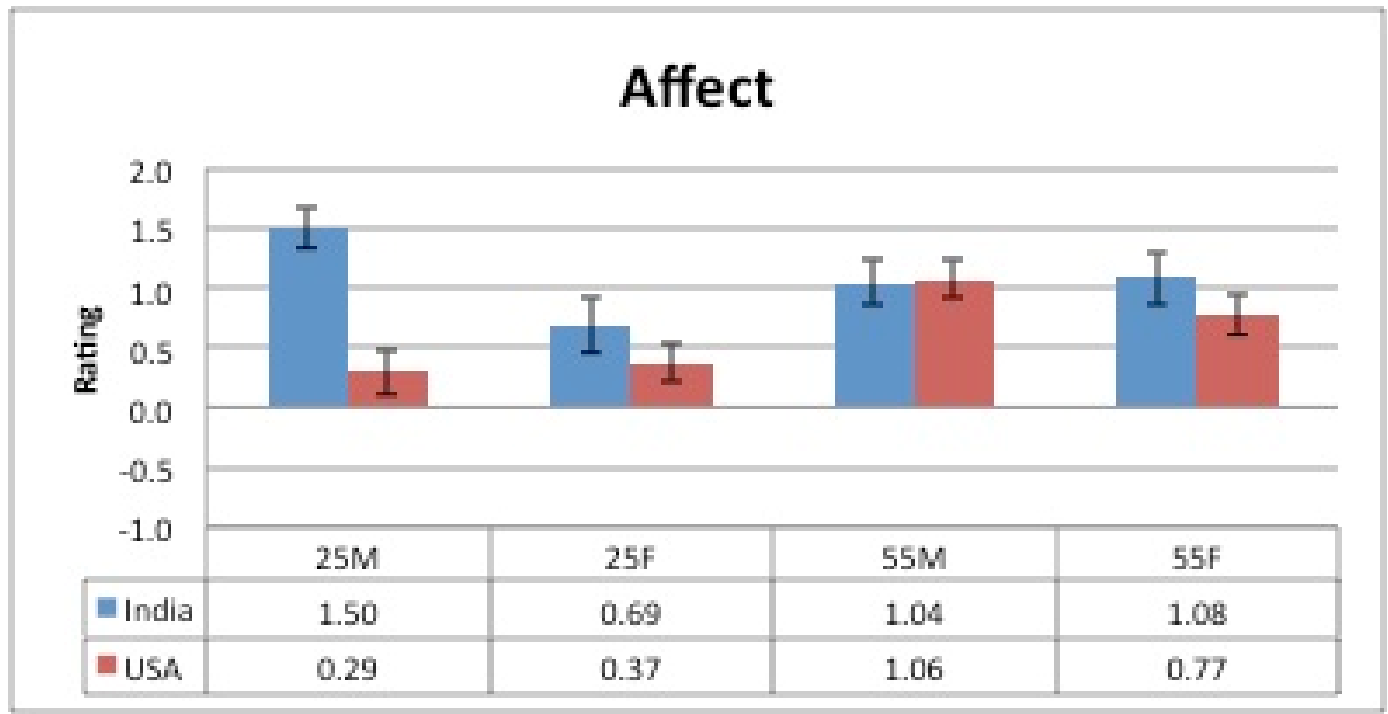

Figure 1. Affect data from the experiment. SE bars are included

A three-way ANOVA was conducted on the Trust data, with age of the air traffic controller, gender of the air traffic controller, and country of origin of the participants as the factors. There was a main effect of Age, $F(1,368)=9.06, p=.003$, partial-eta squared $=.024$, however, this effect was qualified by a significant interaction between Age and Country, $F(1$, $368)=7.06, p=.008$, partial-eta squared $=.019$. There was additionally a three-way interaction between Country, Gender, and Age, $F(1,368)=6.05, p=.014$, partial-eta squared $=.016$. As Figure 2 suggests, the younger male air traffic controllers were trusted more by the Indian participants, while the older air traffic controllers and the younger female air traffic controllers were trusted more by Americans.

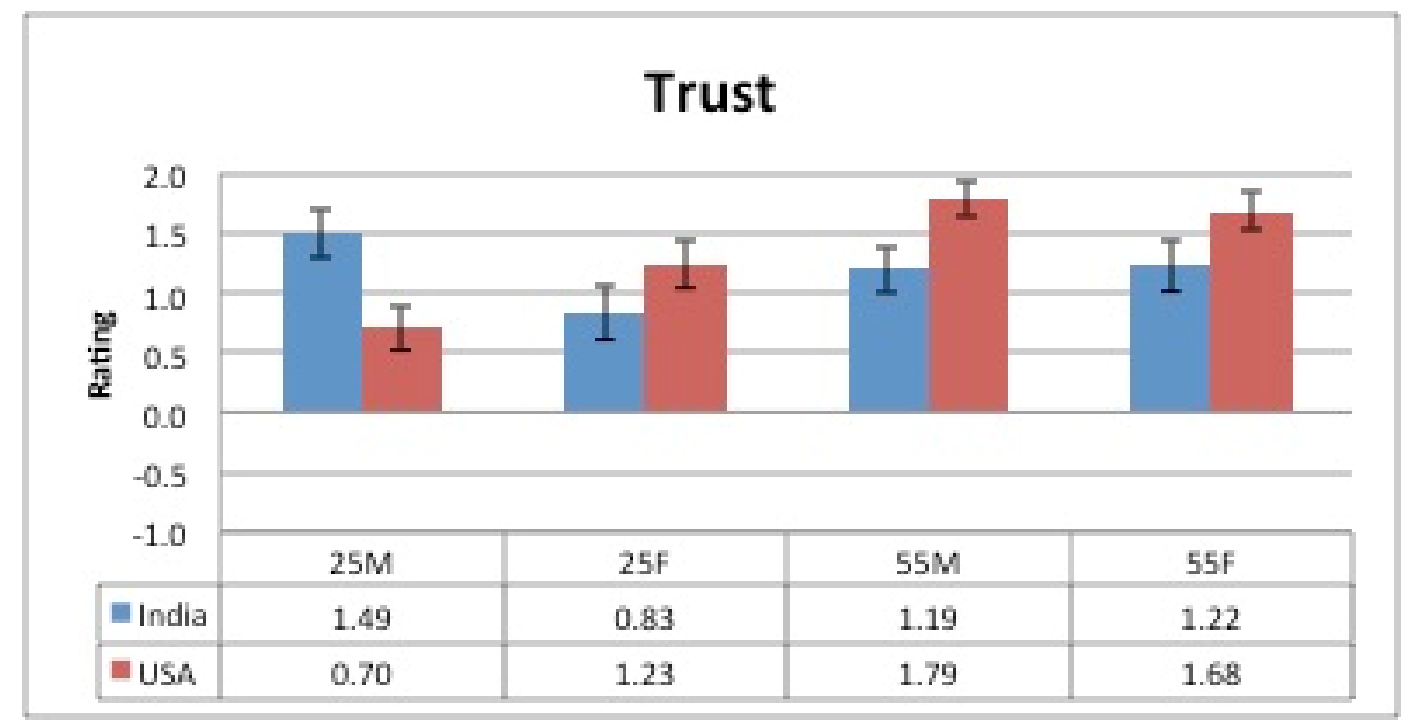

Figure 2. Trust data from the experiment. SE bars are included 


\subsection{Mediation Analyses}

The first mediation analysis was conducted using Indian participants to compare the 25 year old condition to the 55 year old condition. The intent of the mediation analysis is to further understand perception of ability and trust as they relate to the age of the controller. The mandatory retirement age of the controllers has lead to a shortage of controllers for the future. This study seeks to understand how consumers feel towards the abilities and therefore their trust in an aging controller workforce. The paths for this mediation analyses can be found in Figure 3a. In order to conduct the mediation analysis, the correlation between Condition and Trust was first found not to be significant, $r=.017, p=.819$, showing that the initial variable did not correlate with the outcome variable. The data suggest that Affect did not have a mediating effect on the relationship between Condition and Trust.

The second mediation analysis was conducted using American participants to compare the 25 year old condition to the 55 year old condition. The paths for this mediation analyses can be found in Figure $3 \mathrm{~b}$. In order to conduct the mediation analysis, the correlation between Condition and Trust was first found to be significant, $r=.306, p<.001$, showing that the initial variable correlated with the outcome variable. The standardized path coefficients were: condition to affect (Beta $=.255, p<.001)$; affect to trust (Beta $=.607, p<.001)$; condition to trust controlling for affect $($ Beta $=.151 ; p=.009)$. The data suggests that Affect had total mediation on the relationship between Condition and Trust.

A

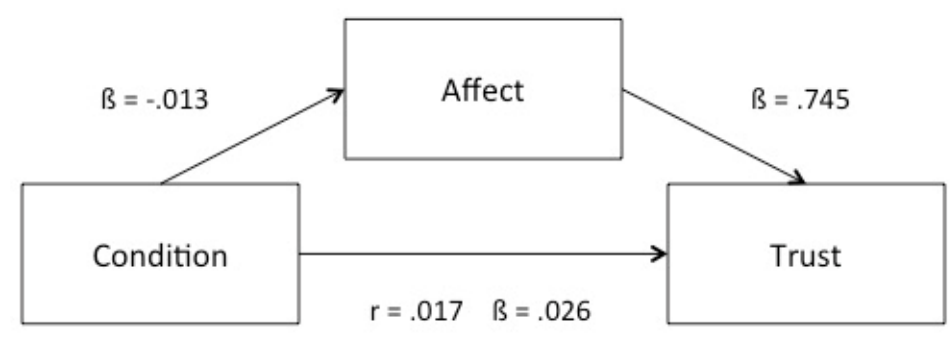

B

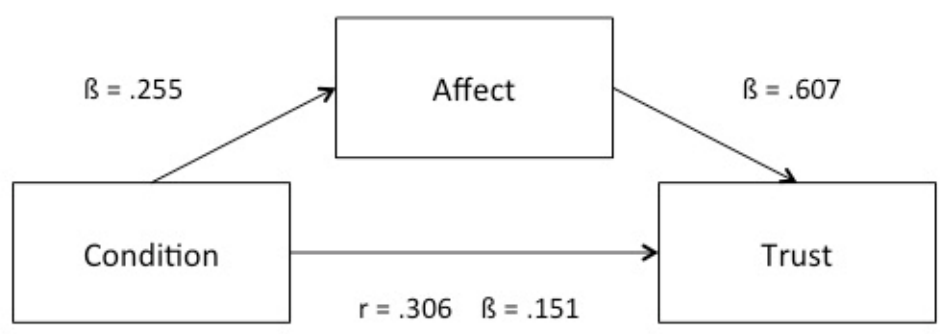

Figure 3. Paths for the mediation analyses

\section{Discussion}

The purpose of the current study is to determine passengers' trust in air traffic controllers, based on the age and gender of the controller. In doing so, the study examines the age-trust 
relationship between passengers and air traffic controllers from two separate cultures. The study focuses on understanding how trust is affected as a result of age and gender by the two cultures. For the purpose of the study, the participants were asked to rate their trust in air traffic controllers who are male or female, 25 years old or 55 years old. The predictions of the study are grounded in the literature on cultural considerations (Hofstede, 1980; Komarraju, et al., 2008), stigmas towards age and gender (Kite \& Johnson, 1988; Kite, Stockdale, Whitley, \& Johnson, 2005; Jackman \& Senter, 1981) as well as previous research in this field (Rice, et. al., 2014; Rice, Mehta, Steelman, \& Winter, 2015; Winter, et. al., 2015; Winter, Rice \& Mehta, 2014).

The first hypothesis stated that there would be differences in trust ratings based on the country of origin of the participant. The data analysis did not support the hypothesis. The results suggested that there were no significant differences in trust between the Indian and American participants. While there was a significant interaction between age and country, the indicated differing levels of trust, a plausible explanation could be that all the participants trust the air traffic controllers. The travelling public through some exposure to aviation might understand the intricate nature of the aviation system, and therefore understand the need for controllers.

The second hypothesis stated, that there would be differences in trust ratings based on the age of the target air traffic controller in the scenarios. The results revealed that the American participants trusted the older controller (55years old) more than the younger controller (25 years old). The results also showed that the Indians trusted the younger controller more so along as he was male. It is interesting to see that Americans trust older more experienced controllers more whereas Indians trust younger controllers more. It is possible that the reason for this lies in the cultural differences between Indians and Americans. One plausible explanation towards the tendency of Americans to trust the older controllers more is that Americans probably trust the experience of a senior 55 year old controller over that of a 25 year old; on average, older workers have more experience in their field. Conversely, while Indian culture tends to revere and respect their elders, it is plausible that the participants may believe that the younger controller is more capable of handling the physical and mental stressors associated with being a controller. The differences in trust can be connected back to the differences in cultural values of each nation.

The third hypothesis stated that there would be differences in trust ratings based on the gender of the target air traffic controller in the scenarios. Results showed that Indians had an affinity towards trusting the male controllers over the female counterparts. The explanation for this could potentially be found on a cultural basis. India is known to be a patriarchal culture where the role of a man is considered to be that of the breadwinner and the head of the family. Most high risk jobs are therefore also attributed towards being male dominated. It is therefore possible that Indians trust the male controller more.

The fourth hypothesis predicted that there would be an interaction between the three independent variables. The data suggested that there was a significant interaction between age and country, and that there was additionally a three-way interaction between country, 
gender, and age. The interactions suggest that the American participants trusted the older controllers and younger female controllers more than their Indian counterparts. However the Indian participants trusted the younger air traffic controllers more, so long as they were male. A plausible explanation for this could lie in the cultural differences between the two nations as they relate to gender and age. Indian might trust younger controllers more due to their mental and physical capability, however their gender biases against the female workforce may impact their trust levels. Conversely, American participants may trust experience over perceived ability of the younger controllers regardless of gender.

The last research prediction stated that affect would mediate the relationship between the conditions and trustworthiness ratings of the air traffic controllers. The results of the study supported this hypothesis, but only for the American participants. The data suggested that affect mediated the relationship between the scenario and the trust ratings for the American participants, but not the Indian participants. This suggests that the decisions of trust were partially based on emotions for the American participants. One plausible explanation could be that in a country like the United States, the news coverage of failures within the aviation system is more salient, and all errors and mistakes are well documented and publicized. This could infer that American participants may be more aware of the potential dangers and therefore be more afraid of the same, thereby allowing their emotions to play a larger factor in their decisions.

\subsection{Limitations}

Limitations are to be expected as part of any research study. One of the main limitations of the current study is that data is collected using the online survey tool, Amazon's ${ }^{\circledR}$ Mechanical Turk ${ }^{\circledR}$. Certain risk exposures arise due to the lack of control of the testing environment, as it is an online medium. However, previous research has suggested that MTurk data is as reliable as laboratory data (Buhrmester, Kwang, \& Gosling, 2011; Germine, et al., 2012). Due to participants being compensated for their time to complete the study, it is important to note the same as a limitation of the study. Compensation could have had an impact on the mindset of the consumer while participating in the study.

Additionally, a limitation of the impact of the findings is that the results are a one-time snapshot of consumer perceptions over the time frame that this study was completed. These findings are relevant to the perceptions of today's consumers, but results may vary in future research with an increase in the understanding of the workings of the aviation industry. Furthermore, in a realistic setting, the passengers would not be aware of the controller's age or gender, and which does pose a limitation on the practical implications of this study. Due to the fact that this study only utilizes India and the United States, it is unfair to apply these findings to a global perspective, even if they do provide insight into the cultural differences of consumers' perceptions across the globe.

\subsection{Practical Implications and Future Research}

The aim of this research study was to provide an insight into the perceptions of the travelling public regarding air traffic controllers with the hope of identifying information that is of 
practical use to the aviation industry. Being a consumer-oriented field, the aviation industry is widely focused on the views of the passengers. The management of Air Traffic is one of the most crucial aspects of keeping air traffic safe. Controllers are of paramount importance to the entire air space system, and therefore understanding the consumers' trust in them is of interest to the industry. While gender differences and ageism are well-documented (Blackburn, Browne, Brooks, and Jarman, 2002; Kite \& Johnson, 1988; Kite, Stockdale, Whitley, \& Johnson, 2005; Jackman and Senter, 1981) areas of interest to research, this study is likely the first to apply those mindsets to the Air Traffic control sector. Additionally, this study provides insight into the mindset of the consumers and suggests that some are basing their decisions on emotions.

In theory, another important practical benefit of the research is to identify which age and gender of air traffic controller is trusted the most by passengers. While this may not directly impact hiring structures at the government level, an understanding of the consumers' trust is of practical use to decision makers. As mentioned earlier, these findings are simply a one time analysis of the current views of the travelling public, and future research may seek to determine if the perceptions of the public have changed over time. To address the issue of global generalizability, future studies may seek to poll consumers from different countries all over the world to gain a more in depth perspective of consumers' trust.

\section{Conclusion}

Air Traffic Control is one piece of an intricate network that makes up the airspace system. It is a vital component that ensures the smooth operation and safety of flights, and therefore is a task of significant responsibility. Air traffic controllers are often exposed to high stress situations and the job itself can be physically and mentally demanding. It is for this reason that the health, and age of controllers is of importance. The study shows that while Americans trust older controllers more, while Indians only trusted younger controllers more so long as they were male controllers. It is also interesting to note that while affect mediated the relationship between the condition and trust for the American participants, it did not for their Indian counterparts. This suggests that Americans were basing their decisions on emotions. This research has practical implication on the industry as it provides a new level of understanding of the consumer's levels of trust in different areas of the industry.

\section{References}

Adapa, S. (2008). Adoption of internet shopping: Cultural considerations in India and Australia, Journal of Internet Banking and Commerce, 13(2), 1-17.

Ashmore, R. D., \& Del Boca, F. K. (1981). Conceptual approaches to stereotypes and stereotyping. Cognitive processes in stereotyping and intergroup behavior, 1, 35.

Blackburn, R.M., Browne, J., Brooks, B. and Jarman, J. (2002). Explaining gender segregation, British Journal of Sociology, 53, 513 - 536. http://dx.doi.org/10.1080/0007131022000021461

Blunk, S. S., Clark, D. E., \& McGibany, J. M. (2006). Evaluating the long-run impacts of the 
9/11 terrorist attacks on US domestic airline travel. Applied Economics, 38(4), 363-370. http://dx.doi.org/10.1080/00036840500367930

Bochner, S. (1994). Cross-Cultural Differences in the self concept a test of Hofstede's individualism/collectivism distinction. Journal of cross-cultural psychology, 25(2), 273-283. http://dx.doi.org/10.1177/0022022194252007

Bugental, D, B., \& Hehman, J. A. (2007). Ageism: A review of research and policy implications. Social Issues and Policy Review, 1, 173-216. http://dx.doi.org/10.1111/j.1751-2409.2007.00007.x

Buhrmester, M., Kwang, T., \& Gosling, S. D. (2011). Amazon's Mechanical Turk: A new source of inexpensive, yet high-quality data? Perspectives on Psychological Science, 6(3), 3-5. http://dx.doi.org/10.1177/1745691610393980

Burns, J. (2006). Racial stereotypes, stigma and trust in post-apartheid South Africa. Economic Modelling, 23(5), 805-821. http://dx.doi.org/10.1016/j.econmod.2005.10.008

Brigham, J. C. (1971). Ethnic stereotypes. Psychological bulletin, 76(1), 15-38. http://dx.doi.org/10.1037/h0031446

Cleveland, J. N., \& Landy, F. J. (1983). The effects of person and job stereotypes on two personnel decisions. Journal of Applied Psychology, 68, 609-619. http://dx.doi.org/10.1037/0021-9010.68.4.609

Cuddy, A. J. C., Norton, M. I. \& Fiske, S. T. (2005). This old stereotype: The pervasiveness and persistence of the elderly stereotype. Journal of Social Issues, 61, 267-285. http://dx.doi.org/10.1111/j.1540-4560.2005.00405.x

Craig, C. S., \& Douglas, S. P. (2006). Beyond national culture: implications of cultural dynamics for consumer research. International Marketing Review, 26(3), 322-342. http://dx.doi.org/10.1108/02651330610670479

Crocker, J., Major, B., \& Steele, C. (1998). Social stigma. In D. T. Gilbet \& S. T. Fiske (Eds.), The handbook of social psychology (pp. 504-553). New York, NY: McGraw-Hill.

Crocker, J., Voelk1, K., Testa, M., \& Major, B. (1991). Social stigma: The affective consequences of attributional ambiguity. Journal of Personality and Social Psychology, 60, 218-228. http://dx.doi.org/10.1037/0022-3514.60.2.218

Deutsch, M. (1958). Trust and suspicion. The Journal of Conflict Resolution, 2, 265-279. http://dx.doi.org/10.1177/002200275800200401

Eckel, C. C., \& Wilson, R. K. (2004). Is trust a risky decision? Journal of Economic Behavior \& Organization, 55, 447-465. http://dx.doi.org/10.1016/j.jebo.2003.11.003

Ergeneli, A., Saglam, G., \& Metin, S. (2007). Psychological empowerment and its relationship to trust in immediate managers. Journal of Business Research, 60, 41-49. http://dx.doi.org/10.1016/j.jbusres.2006.09.012 
Eagly, A. H., \& Steffen, V. J. (1989). Gender stereotypes stem from the distribution of women and men into social roles. Journal of Personality and Social Psychology, 46, 735-754. http://dx.doi.org/10.1037/0022-3514.46.4.735

Faure, G. O. \& Sjostedt, G. (1993). Culture and negotiation: An introduction, Newbury Park: Sage Publications.

Foddy, M., Platow, M.J., \& Yamagishi, T. (2009). Group-based trust in strangers: The role of stereotypes and expectations. Psychological Science, 20, 419-422. http://dx.doi.org/10.1111/j.1467-9280.2009.02312.x

Gekoski, W. L., \& Knox, V. J. (1990). Ageism or healthism? Perceptions based on age and health status. Journal of Aging and Health, 2, 15-27. http://dx.doi.org/10.1177/089826439000200102

Germine, L., Nakayama, K., Duchaine, B.C., Chabris, C.F., Chatterjee, G., \& Wilmer, J.B. (2012). Is the web as good as the lab? Comparable performance from web and lab in cognitive/perceptual experiments. Psychonomic Bulletin \& Review, 19(5), 847-857. http://dx.doi.org/10.3758/s13423-012-0296-9

Han, S. \& Shavitt, S. (1994). Persusion and Culture: Advertising Appeals in Individualistic and Collectivistic Societies. Journal of Experimental Social Psychology, 30, 326-350. http://dx.doi.org/10.1006/jesp.1994.1016

Helmreich, R. L. (2000). Culture and error in space: Implications from analog environments. Aviation, Space, and Environmental Medicine, 71(9-11), 133-139.

Hofstede, G (1980). Culture's Consequences: National Differences in Thinking and Organizing. California: Sage Press.

Hofstede, G. (2001). Culture 's Consequences: Comparing Values, Behaviors Institutions, and Organizations across Nations - 2nd Edition, Thousand Oaks: Sage Publications.

Jackman, M. R., \& Senter, M. S. (1981). Beliefs about race, gender, and social class different, therefore unequal: Beliefs about trait differences between groups of unequal status. In D. J. Treiman \& R. V. Robinson (Eds.) Research in stratification of mobility (Vol. 2). Greenwich, CT: JAI Press.

Jones, E. E., Farina, A., Hastorf, A. H., Markus, H., Miller, D. T., \& Scott, R. A. (1984). Social stigma: The psychology of marked relationships. New York, NY: W.H. Freeman.

Kashima, Y., Callan, V. J., Triandis, H. C., Dunnette, M. D., \& Hough, L. M. (Eds.) (1994). Handbook of industrial and organizational psychology. Palo Alto, CA: Consulting Psychologists Press.

Kenny, D. A. (2011). Mediation. Retrieved from http://davidakenny.net/cm/mediate.html on Feb 28, 2012.

Kite, M. E., Deaux, K., \& Miele, M. (1991). Stereotypes of young and old: Does age outweigh gender? Psychology and Aging, 6, 19-27. 
http://dx.doi.org/10.1037/0882-7974.6.1.19

Kite, M. E. \& Johnson, B. T. (1988). Attitudes toward older and younger adults: A meta-analysis. Psychology and Aging, 3, 233-244. http://dx.doi.org/10.1037/0882-7974.3.3.233

Kite, M. E., Stockdale, G. D., Whitley, B. E. \& Johnson, B. T. (2005). Attitudes toward younger and older adults: An updated meta-analytic review. Journal of Social Issues, 61, 242-262. http://dx.doi.org/10.1111/j.1540-4560.2005.00404.x

Komarraju, M., Dollinger, S. J., \& Lovell, J. L. (2008). Individualism-collectivism in horizontal and vertical directions as predictors of conflict management styles. International $\begin{array}{llll}\text { Journal of Conflict } & \text { Management, } & \text { 19(1), }\end{array}$ http://dx.doi.org/10.1108/10444060810849164

Kongsompong, K., Green, R.T., Patterson, P.C. (2009). Collectivism and Social Influence in the Buying Decision: A Four Country Study of Inter-and-Intra-National Differences. $\begin{array}{llll}\text { Australasian Marketing } & \text { Journal, } & \text { 17(3). }\end{array}$ http://dx.doi.org/10.1016/j.ausmj.2009.05.013

Lee, J. D., \& See, A. K. (2004). Trust in automation: Designing for appropriate reliance. Human Factors, 46, 50-80. http://dx.doi.org/10.1518/hfes.46.1.50.30392

Levy, B. R. \& Banaji, M. R. (2002). Implicit ageism. In T. D. Nelson (Ed.), Ageism: Stereotyping and prejudice against older persons (pp. 49-76). Cambridge, MA: MIT Press.

Markus, H. R., \& Kitayama, S. (1991). Culture and the self: Implications for cognition, emotion, and motivation. Psychological review, 98(2), 224-253. http://dx.doi.org/10.1037/0033-295X.98.2.224

Mayer, R. C., Davis, J. H., \& Schoorman, F. D. (1995). An integrative model of organizational trust. Academy of management review, 20(3), 709-734.

McCann, R., \& Giles, H. (2002). Ageism in the workplace: A communication perspective. In T. D. Nelson (Ed.), Ageism: Stereotyping and prejudice against older persons (pp. 163-199). Cambridge, MA: MIT Press.

McCann, L. (2003). Age discrimination in employment legislation in the United States experience. AARP Foundation Litigation.

NATCA. "NATCA, A History of Air Traffic Control." Web. http://www.natca.org/ULWSiteResources/natcaweb/Resources/file/Media\%20Center/ATCHis tory.pdf

Platow, M. J., Foddy, M., Yamagishi, T., Lim, L., \& Chow, A. (2012). Two experimental tests of trust in in-group strangers: The moderating role of common knowledge of group membership. European Journal of Social Psychology, 42, 30-35. http://dx.doi.org/10.1002/ejsp.852

Rice, S., Kraemer, K., Winter, S. R., Mehta, R., Dunbar, V., Rosser, T. G., \& Moore, J. C. 
(2014). Passengers from India and the United States Have Differential Opinions about Autonomous Auto-Pilots for Commercial Flights. International Journal of Aviation, Aeronautics, and Aerospace, 1(1). Retrieved from http://commons.erau.edu/ijaaa/vol1/iss1/3. http://dx.doi.org/10.15394/ijaaa.2014.1004

Rice, S., Mehta, R., Steelman, L. \& Winter, S.R. (2014). A trustworthiness of commercial airline pilots (T-CAP) scale for Indian consumers. International Journal of Aviation, Aeronautics, and Aerospace, 1(3). Retrieved from http://commons.erau.edu/ijaaa/vol1/iss3/3

Rice, S., Trafimow, D., Hughes, J., \& Hunt, G. (2011). Extending a courtesy stigma to a computer programmer, his work product, and his associates. International Journal of Technology, Knowledge, and Society, 7, 79-91.

Robbins, S. P., \& Judge, T. (2008). Organizational Behavior, 13th revisited edition. New Jersey.

Rupp, D. E., Vodanovich, S. J., \& Crede, M. (2006). Age bias in the workplace: The impact of ageism and casual attributions. Journal of Applied Social Psychology, 36(6), 1337-1364. http://dx.doi.org/10.1111/j.0021-9029.2006.00062.x

Salden, R. J., Paas, F., Broers, N. J., \& Van Merriënboer, J. J. (2004). Mental effort and performance as determinants for the dynamic selection of learning tasks in air traffic control training. Instructional science, $\quad 32(1-2), \quad 153-172$. http://dx.doi.org/10.1023/B:TRUC.0000021814.03996.ff

Triandis, H. C. (1984). A Theoretical Framework for the Ore Efficient Construction of Cultural Assimilators. International Journal of Intercultural Relations, 8(3), 301-330. http://dx.doi.org/10.1016/0147-1767(84)90029-4

Stroebe, W., \& Insko, C. A. (1989). Stereotype, prejudice, and discrimination: Changing conceptions in theory and research. In Stereotyping and prejudice(pp. 3-34). Springer New York. http://dx.doi.org/10.1007/978-1-4612-3582-8_1

Williams, A., \& Nussbaum, J. (2001). Intergenerational Communication Across the Lifespan. Mahwah, NJ : Lawrence Erlbaum.

Williams, J. E., Satterwhite, R. C., \& Best, D. L. (1999). Pancultural gender stereotypes revisited: The Five Factor Model. Sex Roles, 40, 513-525. http://dx.doi.org/10.1023/A:1018831928829

Williams, J. E., Satterwhite, R. C., \& Best, D. L. (2000). Five-factor gender stereotypes in 27 countries. Paper presented at the XV Congress of the International Association for Cross-Cultural Psychology, Pultusk, Poland.

Winter, S. R., Rice, S., \& Mehta, R. (2014). Aviation Consumers' Trust in Pilots: A Cognitive or Emotional Function. International Journal of Aviation, Aeronautics, and Aerospace, 1(1). Retrieved from http://commons.erau.edu/ijaaa/vol1/iss1/2. http://dx.doi.org/10.15394/ijaaa.2014.1003 


\section{Macrothink}

International Journal of Social Science Research

ISSN $2327-5510$ 2016, Vol. 4, No. 1

Winter, S. R., Rice, S., Mehta, R., Cremer, I., Reid, K. M., Rosser, T. R., \& Moore, J. C. (2015). Indian and American consumer perceptions of cockpit configuration. Journal of Air Transport Management, 42, 226-231. http://dx.doi.org/10.1016/j.jairtraman.2014.11.003

\section{Copyright Disclaimer}

Copyright for this article is retained by the author(s), with first publication rights granted to the journal.

This is an open-access article distributed under the terms and conditions of the Creative Commons Attribution license (http://creativecommons.org/licenses/by/3.0/). 